\title{
Research on the Supervision and Regulation Mode of Production Safety in China, Germany and Canada
}

\author{
Yixu Gong \\ Department of Risk and Emergency Technology, Beijing Academy of Safety Science and Technology, Beijing, China \\ Email: fiona_gyx2013@163.com
}

How to cite this paper: Gong, Y.X. (2019) Research on the Supervision and Regulation Mode of Production Safety in China, Germany and Canada. World Journal of Engineering and Technology, 7, 83-90. https://doi.org/10.4236/wjet.2019.72B010

Received: April 28, 2019

Accepted: May 28, 2019

Published: May 31, 2019

\begin{abstract}
China is a developing country with rapid economic development and has made many remarkable achievements. However, the foundation of production safety is relatively weak, and the situation of production safety is still severe behind the rapid economic growth, and there is still a certain gap compared with Germany, Canada and other developed countries. Therefore, this article expounds the theory of safety production supervision mode, and then taking the supervision mode of production safety of Chinese government as the basic research object, from the development course, organization setup and management configuration and so on combing the current (until 2017) safety production supervision mode in Chinese government, and puts forward the status quo in the face of regulatory problems. In addition ,based on the research and analysis of the safety production supervision mode of the German and Canadian governments, the advanced experience and methods of the safety production supervision mode of the two governments are summarized, and through comparison, some suggestions on the supervision mode of production safety suitable for China's national conditions are put forward, which provide theoretical support for the Chinese government or enterprise managers to do a good job in the management of production safety.
\end{abstract}

\section{Keywords}

Production Safety, Regulation, Safety Culture, Occupational Safety and Health

\section{Introduction}

Safe production is the basic guarantee to protect the safety and health of workers, improve the comprehensive national strength and ensure the sustainable development of national economy. At present, China is in a critical period of 
industrialization and urbanization; it has made remarkable achievements because of the rapid economic growth. Behind the rapid economic growth, however, the price paid are the price of frequent production safety accidents, social cost loss, ecological environment deterioration and so on, the above mentioned elements are not only caused massive losses of state property and civil life also bear the huge pressure of public opinion of the international community, as a result, the supervision and regulation of production safety is particularly important.

Under the condition of market economy, enterprises are the main body of responsibility to ensure the safety of production, the improvement of safe production level should rely on the market mechanism. However, due to the differences in legal construction of production safety, investment level of science and technology, social welfare treatment, education popularization, safety culture and other factors, they are difficult to guarantee the safety production through spontaneous market behavior, which need to rely on national supervision to achieve it.

The mode of safety production is the institutional guarantee for the state to implement the supervision, and it is also the basis and premise of doing a good job in production safety. Therefore, this paper provides a reference basis and theoretical support for the development and improvement of China's supervision and regulation of safety production mode, as well as a basic guarantee for China's public safety.

\section{Theoretical Basis of Safety Production Supervision}

In Cihai, "safety production" is defined as a series of measures and activities for preventing the personal and equipment accidents during the production process in order to form a good working environment [1]. In other words, the concept of "Safety production" aims to emphasize the safety of people and things in the production process. However, the term of "safety production" is not a commonly used international term. The concept which is internationally similar to the term of "safety production" is "occupational safety and health" [2].

Supervision generally refers to the control or regulation of a subject based on certain rules in order to make something work normally [3]. Government regulation refers to the regulation and restriction on micro-economic subjects by the government in order to achieve certain public policy objectives under the condition of market economy [4].

In conclusion, the government safety regulation can be understood as government agencies on the basis of its statutory functions and powers, through administrative, legal, economic and other means in the face of the main body (including enterprises and individuals)of the market economy to constraints and restrictions on their activities, in order to prevent and remedy market failures, in order to avoid or reduce damage caused by individual economic decision-making, ensure the normal operation of the market economy [1].

\section{The Current Situation of the Safety Production Supervision in China}

The current supervision systems of safety production in China have the charac- 
teristics of combining comprehensive supervision with industry supervision, national supervision with local supervision, and government supervision with other supervision [5].

\subsection{Comprehensive Supervision with Industry Supervision}

In China's legal system of safety production, the Law of PRC on Safe Production is the first comprehensive safe production law in China, which defines the basic requirements for safety production [6]. The Law of PRC on Fire Prevention Regulation, the Law of PRC on road traffic safety, The Law of PRC on special equipment safety and other professional laws and regulations regulate the work of production safety in various industries. In accordance with Chinese laws and regulations, safety production supervision departments are responsible for comprehensive supervision of work safety, the public security, transportation, housing, urban-rural construction, quality and technical supervision departments and other relevant departments are responsible for professional supervision of safety production in accordance with their professional safety laws and regulations in the industry [6].

\subsection{National Supervision with Local Supervision}

Based on the industry regulation, China has implemented a national supervisory system in some specific industry field, such as civil aviation, railways, shipping, electric power, coal, etc., in order to improve the professional level of supervision, China has set up a number of professional safety supervision institutions, which are basically vertically managed and have no relationship with local governments. In terms of personnel and business, they are independent from local leaders and can minimize the interference of local governments [6].

\subsection{Government Supervision with Other Supervision}

The supervision of Chinese government mainly includes: the work safety supervision department and other departments responsible for the supervision and administration of safety production [7]. At the same time, China also actively encourage others to participate in production safety supervision, for example, encouraging the masses inform against hidden danger and accident, organizing workers to participate in and supervise the work of production safety of enterprises with the advantages of trade unions, giving full play to the supervision role of news media by public opinion, and supporting intermediary institutions to provide technical services for work safety etc. [8].

\section{The Problems of the Safety Production Supervision in China}

\subsection{The Legal System of Safety Production Is Not Perfect}

As of 2014, China has over 400 major laws and regulations concerning production safety, occupational health and labor protection, which include more than 
50 administrative regulations, more than 30 state council notices on production safety, and more than 100 departmental rules and regulations, in addition, there are hundreds of national standards, industrial standards and local regulations on production safety [3]. However, there are some conflicts between various legal provisions, which restrict the supervision and law enforcement of work safety in China. For example, after implementing the regulations on the reporting, investigation and handling of production safety accidents in China, the investigation and punishment of production safety liability accidents shall be jointly completed by a joint investigation team composed of the national government and the functional department of supervision and administration of production safety, those two subjects have overlapping and overlapping functions in the work of accident investigation and administrative punishment, and it may be difficult for them to investigate and deal with the accident [9].

\subsection{The Incentive Mechanism Is Not Perfect}

At present, the restraint of safety supervision personnel in China is more than the incentive, and the absence of incentive mechanism makes it difficult to mobilize the work enthusiasm of safety supervision personnel [10]. On the spiritual level, once a safety production accident occurs, no matter how hard the work of the early safety supervisors is, in the case of strict accountability, the accident prevention work done by the safety supervisors may be ignored or less proposed, making the safety production supervision has become a high-risk occupation, which has certainly hampered the work enthusiasm of safety supervisors, and indirectly caused it to be difficult for safety regulators to absorb and retain outstanding talents [11].

\subsection{The Social Participation Mechanism Is Not Defective}

The issue of safety production is not a single issue of government regulation. It also requires the organization of social organizations to play its role in the supervision and management of production safety. The organizations in these social groups include: trade unions, non-governmental organizations and insurance institutions. However, the Chinese social supervision force has not been fully utilized. The main reason is that the participation mechanism is not perfect, which has affected the enthusiasm of social forces to participate. For example, the China Safety and Health Industry Association and other non-government organizations are still in the development stage of safeguarding the interests of the industry [12]. The role of safety production supervision has not been fully paid attention to and developed; the mandatory work injury insurance system has been guaranteed to a certain extent. Workers can obtain certain economic compensation after being injured by accidents and suffering from occupational diseases [8]. However, at present, China's insurance system is "heavy compensation and light prevention", and the industrial injury insurance institutions have not better played their role in accident prevention. 


\section{Overview of the System of Safety Production Supervision Mode in Developed Countries}

Throughout the world, legislation, inspection and industrial injury insurance are the three main pillars for ensuring the smooth implementation of safety production in the market economy. "No rules are not square", the safety production legislation protects the safety and health of workers from the legal level, guarantees the interests of production and business units, employees and the legal rights that they should enjoy, and guarantees the social production resources and the wealth of the country and the people and the life safety; safety inspection is to investigate the potential hidden dangers in production work from the practical application level and timely rectification, so as to lay a good foundation for the smooth promotion of government safety production supervision work; work injury insurance is a compulsory public insurance plan developed on the basis of the employer responsibility system. It aims to protect the economic interests of workers from the aspects of welfare benefits, compensation, and medical rehabilitation.

\subsection{The Safety Production Supervision Mode in German}

Germany is an industrial power and an economic powerhouse, and its annual number of safe production accidents is one of the lowest countries in the world. Germany's safety production work is at the forefront, thanks to its complete legal system, strict law enforcement supervision, good safety awareness and working environment, and a reliable accident insurance system [5]. In addition, Germany's safety production supervision and management adopts a "dual track system" supervision system: the national labor protection work and labor supervision carried out by the state labor protection agencies are under the responsibility of the state, federal states and state ministries and commissions; the labor protection activities and supervision carried out by the statutory accident insurance institutions are organized by the Industrial Accident Insurance Association and the Accident Insurance Company [13], both of them have the responsibility of setting labor safety standards, conducting consultation and prevention, implementing supervision and monitoring, and conducting accident investigation. Moreover, the Industrial Accident Insurance Association is not a part of the federal government and the state government, nor does it belong to any government department. However, it has the statutory nature of labor protection supervision and management, and is a self-managed public law entity that is not for profit [14].

\subsection{The Safety Production Supervision Mode in Canada}

Canada is a federal state with a three-tiered federal, provincial, and administrative system. It includes 1 federal government, 10 provincial governments and 3 provincial administrative regions. As one of the largest economies in the world, Canada is rich in natural resources, developed in manufacturing and high-tech 
industries, and primary manufacturing and agriculture are also the main pillars of the national economy [14]. The federal government is responsible for the formulation of labor security, working conditions, occupational health and safety regulations; the provincial government is responsible for formulating labor standards for minimum wages, compensation for work-related injuries, vacations, and overtime; provincial administrative district governments focus on providing employment assistance and social protection assistance to vulnerable groups [14]. In addition, strengthening the national safety awareness is another important part of the Canadian government to ensure the continuous and stable improvement of the production safety situation. Moreover, Canada holds a national occupational safety and health "safety week" in the first week of June each year, for example, posting "safety and health week" posters, distributing and showing free information and videos on safety and health; inviting security experts to present security knowledge to the enterprise; organizing seminars; announcing the list of workers, departments and leaders who have made outstanding achievements in safety and health work [15].

\section{Suggestions on Improving the Supervision Mode of Safety Production in China}

Compared with developed countries, although China has some deficiencies in the supervision of production safety, it can better adapt to the current social production situation in China. Based on the analysis of the German and Canadian governments' supervision modes of safety production, in combination with China's current national conditions, the following three recommendations are proposed.

\subsection{Establish and Improve China's Safety Production Laws and Regulations}

An important duty of safety production supervision is to supervise enterprises according to laws and regulations, departmental rules and regulations. The legal provisions are the basis for the establishment of the regulatory body, and it is the guarantee that the regulatory agency performs its duties and exercises its rights. Although there are many laws and regulations on production safety in China, there are ambiguous definitions of duties and contradictions between legal provisions. According to the research, German industry associations develop safety standards based on the current state of the industry to promote safe production [5], therefore, to learn from foreign advanced experience, China should gradually implement the principles of institutional setting and legislative advancement, conduct in-depth investigations into the safety production work of enterprises, and introduce a safety production legal system suitable for China's national conditions.

\subsection{Establish a Safety Management System That Adapts to the Market Economy}

According to the characteristics of China's market economy, China should con- 
tinuously improve the safety management system adapted to the market economy in view of the emerging new situations and problems; governments at all levels have set up work safety supervision and administration organizations and staffed them with professional and full-time supervisors to improve their professional quality and law enforcement ability, clarify the scope and responsibilities of supervision, and form and improve safety supervision networks; in addition, the work safety work pattern of "unified government leadership, supervision by departments in accordance with the law, overall responsibility of enterprises, participation of the masses in supervision, and broad support of the whole society" should be established, and their respective safety responsibilities and obligations should be defined in more detail, so as to ensure that each party's main responsibility for safety is implemented in place.

\subsection{Strengthen Administrative Law Enforcement and Implement the "Heavy Penalty" Mechanism}

In China, there may still be "laws that are not law-abiding and law enforcement is not strict", enterprises and employees violate the laws, regulations and systems of production safety, which hinders the implementation of the enterprise production safety responsibility system, and causes various types of production safety accidents to occur frequently due to improper rectification of hidden accidents [11]. However, in economically developed countries, for example, "heavy penalty mechanism" is one of the important means for the Canadian government to supervise production safety. Under the effect of "heavy penalty", Canadian enterprises and their bosses, managers and employees dare not take legal risks with their economic interests due to the high cost of breaking the law [7]. Therefore, the Chinese government can learn from foreign experience to strengthen administrative law enforcement. The responsible units and responsible persons responsible for the safety accidents shall be imposed high fines, and those responsible for serious violations of the law shall be investigated for criminal responsibility according to law, so that those enterprises and individuals who have the chance to survive will not dare to try their own methods and truly play a warning role.

\section{Fund}

Fund project number: Z181100009018003.

\section{Conflicts of Interest}

The author declares no conflicts of interest regarding the publication of this paper.

\section{References}

[1] Cheng, W.T. (2013) China's Safety Production Situation, Gaps and Countermeasures. Coal Industry Press. 
[2] Liu, T.M. (2006) Knowledge of Safe Production Management. China Encyclopedia Publishing House.

[3] Hong, W.L. (2008) Safety Production Monitoring. China Science and Technology Press.

[4] Xiao, X.Z. (2006) Government Regulation Theory and Policy. Dongbei University of Finance and Economics Press.

[5] Zhang, B.F., Liu, S.Y. and Li, Z.X. (2009) Safety and Health Management and Standard System in German Mines and Their Characteristics. The Standard of Science. 45-48.

[6] Liu, T.M. (2009) Several Scientific Problems concerning Production Safety in China. Science press.

[7] Wang, J.Z. (2006) Theory and Practice of Comprehensive Prevention System for Safety Production. Shandong University Press.

[8] Qiu, C. (2007) On Comprehensive Management in Safety Production. Safety, 19-22.

[9] Zhang, J. (2007) How to Straighten out the Comprehensive Supervision of Safety Production and Industry Supervision. Safety production work research.

[10] Liu, T.M. (2009) China's Safe Production for 60 Years. China Labor and Social Security Publishing House.

[11] Guan, E.T. and Qin, D.Z. (2012) Research on Long-Term Mechanism of Safety Production Management. Science Press.

[12] Wang, X.Z. (2005) Research on Perfecting China's Safety Production Supervision and Management System. Coal Industry Press.

[13] World Health Organization (2012) Profile of Occupational Health System in Germany. The WHO Regional Office.

[14] Ministry of Science and Technology Research Group (2006) International Safety Production Development Report. Science and Technology Literature Publishing House.

[15] The Minister of Justice in Canada (2018) Canada Occupational Health and Safety Regulations. 